\title{
Soluble polysaccharide and biomass of red microalga Porphyridium sp. alter intestinal morphology and reduce serum cholesterol in rats
}

\author{
Irit Dvir ${ }^{1}$, Reuven Chayoth ${ }^{2}$, Uriel Sod-Moriah ${ }^{2}$, Shraga Shany $^{3}$, Abraham Nyska ${ }^{4}$, Aliza H. Stark ${ }^{5}$, \\ Zecharia Madar ${ }^{*}$ and Shoshana Malis Arad ${ }^{1}$ \\ ${ }^{1}$ The Institute for Applied Biosciences, and ${ }^{2}$ Department of Life Sciences, Ben-Gurion University of the Negev, Beer-Sheva \\ 84105, Israel \\ ${ }^{3}$ Faculty of Health Sciences, Ben-Gurion University of the Negev, Clinical Biochemistry Unit, and Soroka University \\ Hospital of Kupat-Holim, Toor Institute, Beer-Sheva 84105, Israel \\ ${ }^{4}$ National Institute of Environmental Health Sciences, Research Triangle Park, NC 27709, USA \\ ${ }^{5}$ Faculty of Agricultural, Food and Environmental Quality Sciences, Institute of Biochemistry, Food Sciences and Nutrition, \\ The Hebrew University of Jerusalem, PO Box 12, Rehovot 76100, Israel
}

(Received 25 August 1999 - Revised 17 April 2000 - Accepted 2 May 2000)

\begin{abstract}
The present study investigated the effects of the red microalga Porphyridium sp. on gastrointestinal physiology and lipid metabolism in male Sprague-Dawley rats. Diets containing dietary fibre from pelleted red microalgal cells (biomass) or their sulfated polysaccharide, pectin or cellulose (control) were fed to rats for a period of $30 \mathrm{~d}$. All three fibre-supplemented diets increased the length of both the small intestine and colon, with a significantly greater effect in rats fed the algal polysaccharide. The polysaccharide also increased mucosa and muscularis cross-sectional area of the jejunum, and caused hypertrophy in the muscularis layer. The algal biomass significantly lowered gastrointestinal transit time by $44 \%$ in comparison with the control rats. Serum and mucosal cholecystokinin levels were lower in rats on the pectin and polysaccharide diets, while cholecystokinin levels in rats fed algal biomass were not different from those in the control animals. In comparison with the control diet, all the experimental diets significantly lowered serum cholesterol levels (22-29\%). Feeding of non-fermentable algal polysaccharide or biomass significantly increased faecal weight and bile acid excretion compared with pectin-fed or control rats. The algal polysaccharide and biomass were thus shown to be potent hypocholesterolaemic agents active at low concentrations in the diet. Both metabolic and morphological changes were observed following consumption of algae, suggesting several possible mechanisms by which the alga affects lipid metabolism. The results presented in the present study encourage the use of red microalga as a functional food.
\end{abstract}

Dietary fibre: Red microalga: Cholesterol: Image analysis

Since ancient times, seaweeds have served as a food source, primarily in Asia. It is now well known that algal biomass serves as a rich source of proteins, lipids, carbohydrates, dietary fibre, minerals and vitamins (Fabregas \& Herrero, 1990; Lopez-Alonso et al. 1992). Consequently, there has been a revival of interest in marine algae as an alternative source of nutrients in Western countries (Mabeau \& Fleurance, 1993). Seaweeds that are rich in undigestible polysaccharides (such as agar, carrageenan and alginate) are widely used as food additives. These algae also constitute potential sources of dietary fibre that differ chemically and physico-chemically from those of land plants, and thus may have different physiological effects on the human body (Lahaye, 1991; Lahaye \& Jegou, 1993). The addition of fibre-rich algal products to the diet could increase overall dietary fibre intake, which has been hypothesized to decrease the prevalence of diseases associated with low dietary fibre intake such as obesity, diabetes, heart disease and cancer (Southgate, 1990).

Red microalgae constitute a new source of dietary fibre.

\footnotetext{
Abbreviations: CCK, cholecystokinin; GTT, gastrointestinal transit tine.

* Corresponding author: Professor Zecharia Madar, present address Faculty of Agricultural, Food and Environmental Quality Sciences, Institute of Biochemistry, Food Sciences and Nutrition, The Hebrew University of Jerusalem, Rehovot 76100, Israel, fax +972 8 9363208, email madar@agri.huji.ac.il
} 
The cells are encapsulated in a cell wall composed of sulfated polysaccharides (about 50-70\% of the biomass), of which the external part dissolves in the medium. The cell-wall polysaccharides are heteropolymers in which the main sugars are xylose, glucose and galactose (Malis Arad, 1988; Geresh \& Malis Arad, 1991). The presence of sulfate groups and glucuronic acid confer a negative charge on these molecules. In addition, red microalgae contain eicosapentaenoic acid (20:5n-3; Bajpai \& Bajpai, 1993; Nuutila et al. 1997).

Consumption of dietary fibre induces both local and systemic responses. Morphological changes in the gastrointestinal tract occur following direct exposure to dietary fibre, while systemic changes occur in carbohydrate and lipid metabolism (Davidson \& McDonald, 1998). The unique chemical and physical characteristics of each fibre source dictate their effects in the body. In addition, the mechanisms by which fibre induces physiological changes are related to its viscosity, fermentability, water-holding capacity, bile acid-binding ability, cation-exchange capacity and faecal-bulking ability (Eastwood \& Morris, 1992). Consumption of soluble fibre is associated with changes in lipid metabolism, including a hypocholesterolaemic effect (Anderson et al. 1994).

The present investigation was undertaken to elucidate the metabolic and morphological effects of polysaccharides and biomass from the red microalga Porphyridium sp. in rats. Results described in the present study indicate that consumption of algae may have great potential as a therapeutic agent.

\section{Materials and methods}

\section{Source of algae and culture conditions}

The unicellular red alga Porphyridium sp. (UTEX 637) was obtained from the culture collection of the University of Texas, Austin, TX, USA. The algae were cultivated outdoors for $21 \mathrm{~d}$ in artificial sea water (Jones et al. 1963), in polyethylene sleeves (Cohen \& Malis Arad, 1989).

\section{Isolation of biomass and polysaccharide}

Algal cultures were harvested by continuous centrifugation (Cepa Z-41; Carl Parberg, Lahr, Schwarzwald, Germany). The pellet containing the algal cells (biomass) was washed with distilled water and centrifuged. The supernatant fraction, containing the soluble polysaccharides excreted by the algae during growth, was dialyzed (to remove salts) and the polysaccharide concentrated by ultrafiltration. Both the polysaccharide and biomass were dried by lyophilization and powdered for use in the present experiment.

\section{Dietary fibre sources and analysis}

Four sources of dietary fibre were used: (1) cellulose (Solka-folc; James River Corp., Hackensack, NJ, USA); (2) pure citrus pectin, methoxy concentration $10 \mathrm{~g} / 100 \mathrm{~g}$ (Sigma, St Louis, MO, USA); (3) Porphyridium sp. cells (biomass); and (4) sulfated polysaccharide of the red
Table 1. Composition of experimental diets* $(\mathrm{g} / \mathrm{kg})$

\begin{tabular}{|c|c|c|c|c|}
\hline $\begin{array}{l}\text { Diet } \\
\text { Ingredient }\end{array}$ & $\begin{array}{c}\text { Algal } \\
\text { polysaccharide }\end{array}$ & $\begin{array}{c}\text { Algal } \\
\text { biomass }\end{array}$ & Pectin & Control \\
\hline Casein & 178 & 166 & 196 & 200 \\
\hline Sucrose & 232 & 232 & 232 & 232 \\
\hline Maize starch & 338 & 304 & 394 & 430 \\
\hline Maize oil & 67 & 59 & 70 & 70 \\
\hline Fibre source & $140 \dagger$ & $190 \ddagger$ & $60 \S$ & $20 \|$ \\
\hline Vitamin mix* & 10 & 10 & 10 & 10 \\
\hline Mineral mix* & 35 & 35 & 35 & 35 \\
\hline DL-methionine & 3 & 3 & 3 & 3 \\
\hline \multicolumn{5}{|c|}{ 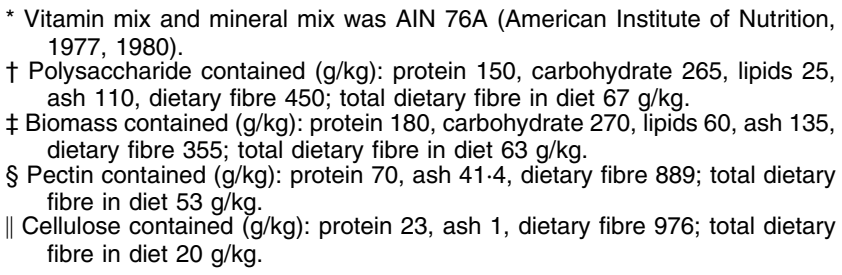 } \\
\hline
\end{tabular}

microalga Porphyridium sp. (prepared as described earlier). Dietary fibre analysis was carried out according to the Association of Official Analytical Chemists standard method (Prosky et al. 1988).

\section{Animals}

Male Sprague-Dawley rats (Harlan, Jerusalem, Israel), each weighing 130-140 g, were housed in individual suspended stainless-steel cages in a controlled environment $\left(22-24^{\circ} \mathrm{C}\right.$ and $12 \mathrm{~h}$ light-dark) with free access to food and water. Animals were kept according to the guidelines laid down by the Animal Care Committee of the Institutes for Applied Research, Ben-Gurion University of the Negev, Israel.

\section{Experimental procedures}

Twenty-eight rats were divided into four groups such that the mean weights of each group were similar. Rats were fed the diets shown in Table 1 (American Institute of Nutrition, 1977, 1980) for a $30 \mathrm{~d}$ period. Every $2-3 \mathrm{~d}$ the animals and faeces were weighed, and food intake was assessed. During the last $4 \mathrm{~d}$ of the experiment, faeces were collected. Gastrointestinal transit time (GTT) was determined during the third week of the experiment. Plasma cholecystokinin (CCK) levels were measured during the fourth week of the experiment and in samples collected at the end of the experiment. After $30 \mathrm{~d}$ of the experiment, food was withheld from the rats overnight (12-14 h), and animals were anaesthetized with chloral hydrate $(100 \mathrm{~g} / \mathrm{l})$. Blood samples were taken from the heart and placed in tubes with or without heparin. Samples were then centrifuged for $10 \mathrm{~min}$ at $1000 \mathrm{~g}$, and plasma or serum was frozen at $-20^{\circ} \mathrm{C}$ until analysed. The entire intestine from the pyloric sphincter to the rectum was removed, extended on a flat surface with minimal stretching, and the length measured. Jejunum and colon samples were taken for histopathological examination. Caecal contents were removed and stored frozen $\left(-20^{\circ} \mathrm{C}\right)$. 


\section{Methodologies}

Gastrointestinal transit time. Rats were intubated with $1.5 \mathrm{ml}$ carmine solution $(10 \mathrm{~g} / \mathrm{l})$ as a marker. The length of time between administration and the first appearance of the marker in the faeces was taken as the GTT.

Determination of plasma lipids. Total plasma cholesterol content was measured by the enzymic colorimetric methods as described by Allain et al. (1974) and LopesVirella et al. (1977). Plasma triacylglycerol levels were determined by the method of Fossati \& Prencipe (1982).

Faecal bile acid analysis. Faecal samples were collected over the last $4 \mathrm{~d}$ of the experiment, weighed, and frozen at $-20^{\circ} \mathrm{C}$. Samples were then dried by lyophilization, and stored in a desiccator for later analysis. Dried faecal matter $(100 \mathrm{mg})$ was extracted overnight with $10 \mathrm{ml}$ chloroformmethanol (2:1, v/v; Folch et al. 1957). $\mathrm{KCl}(3.7 \mathrm{~g} / \mathrm{l} ; 2 \mathrm{ml})$ was then added, and the sample was centrifuged at $1500 \mathrm{~g}$ for $10 \mathrm{~min}$. The upper layer was removed, evaporated to dryness, and dissolved in $1 \mathrm{ml}$ methanol $(500 \mathrm{ml} / \mathrm{l})$. Total bile acids were determined by enzymic analysis using a modified method of Sheltawy \& Losowsky (1975). Each tube content was as follows: phosphate buffer $\mathrm{pH} 10 \cdot 5,2 \mathrm{mmol}$ $\mathrm{NAD} / \mathrm{l}$ and $100 \mu \mathrm{l}$ sample. The reaction was initiated by adding $3 \alpha$-hydroxysteroid dehydrogenase $(0 \cdot 1$ IU per reaction) in a final volume of $1.5 \mathrm{ml}$. After $30 \mathrm{~min}$ at room temperature, the absorbence was measured at $340 \mathrm{~nm}$ to detect NADH formed.

Faecal neutral sterol analysis. A modified method of Searcy \& Bergquist (1960) was used to determine faecal neutral sterol concentrations. Dried faecal samples $(50 \mathrm{mg})$ were saponified with $3 \mathrm{ml}$ ethanolic $\mathrm{KOH}(100 \mathrm{~g} / \mathrm{l})$ for $1 \mathrm{~h}$ at $65^{\circ} \mathrm{C}$. Samples were cooled to room temperature and neutral lipids were extracted with $3 \mathrm{ml}$ water and $5 \mathrm{ml}$ light petroleum (b.p. $40^{\circ} \mathrm{C}-60^{\circ} \mathrm{C}$ ). Mixtures were vortexed for $30 \mathrm{~s}$ and the solvent removed. Second and third extractions with $5 \mathrm{ml}$ and $3 \mathrm{ml}$ light petroleum were then carried out and extracts pooled. The samples were dried under $\mathrm{N}_{2}$ and a colorimetric reaction was carried out in $3 \mathrm{ml}$ acetic acid saturated with $\mathrm{FeSO}_{4}$ and $1 \mathrm{ml} \mathrm{H}_{2} \mathrm{SO}_{4}$. Absorbence was measured at $490 \mathrm{~nm}$ to detect sterol concentrations.

Cholecystokinin. In week 3 of the experiment food was withheld overnight and rats were fed $5 \mathrm{~g}$ of their respective diets over a $2 \mathrm{~h}$ period. At $1 \mathrm{~h}$ after removing the food, blood samples were collected from rat tail tips in preheparinized Eppendorf tubes. Samples were then centrifuged for $10 \mathrm{~min}$ at $1000 \mathrm{~g}$ and plasma was frozen at $-20^{\circ} \mathrm{C}$. Mucosal samples were prepared as follows: duodenal sections were placed on ice and the mucosa scraped off. The mucosal samples were freeze-thawed twice, acidified with $10 \mathrm{~g}$ trifluroacetic acid/l in distilled water, homogenized for $1 \mathrm{~min}$, and centrifuged at $40000 \mathrm{~g}$ for $20 \mathrm{~min}$. Extraction of peptide from the mucosa was carried out with a $\mathrm{C}_{18}$ SEP-COLUMN as described in the general protocol for radioimmunoassay kit (Peninsula Laboratories Inc., Belmont, CA, USA). CCK levels in the blood and in the mucosa samples were also measured using this kit. Protein levels were determined in each mucosa sample, using method of Bradford (1976).

Caecal content viscosity. Frozen caecal contents were defrosted to room temperature and $1 \mathrm{~g}$ (wet weight) was diluted with $10 \mathrm{ml}$ distilled water. Samples were centrifuged at $30000 \mathrm{~g}$ for $30 \mathrm{~min}$. The viscosity of the supernatant fraction was measured at $22^{\circ} \mathrm{C}$ with a Brookfield Digital Viscometer (Brookfield Engineering, Stoughton, MA, USA). Samples with low viscosity $(<0 \cdot 1$ Pa.s) were measured with spindle 18 and shear rate of $39 \cdot 6 / \mathrm{s}$. Samples with high viscosity were measured with spindle 31 and shear rate of $9 \cdot 3 / \mathrm{s}$.

Histopathology. At the termination of the experiment, samples of $10 \mathrm{~mm}$ segments from the jejunum and midcolon were cut out and preserved in buffered formaldehyde $(40 \mathrm{ml} / \mathrm{l})$. Particular attention was paid to quick fixation of the tissues to prevent autolysis; the maximum time from killing to fixing being $5 \mathrm{~min}$. Transversal slices of the intestinal segments, perpendicular to the mucosal surface, were prepared, dehydrated and embedded in paraffin wax. Sections were cut to a thickness of $4-5 \mu \mathrm{m}$ and stained with haematoxylin and eosin. The tissue was well orientated, and the plane of the section passed vertically through the epithelium. In each section, image analysis (GALAI SuperCue3/ScanArray; GALAI, Migdal-Haemek, Israel) was used to determine the area of the mucosa including the villi and crypts, and the underlying submucosa. This layer was easily distinguished from the tunica muscularis layer.

The cell size in the inner circular smooth muscle layer of the tunica muscularis was determined by counting the number of nuclei in a defined area. Three fields were randomly selected, providing a total area of $4.1 \mathrm{~mm}^{2}$. The fields for measurement were selected at random. The principles of the technique used for this computer-aided microscopy are outlined in Slavin et al. (1980). Before applying morphometric quantifications, cross-sections were closely examined for the technical quality (i.e. grade of staining intensity of the nuclei in order to enable accurate identification and discrimination from the cytoplasm background). Before each measurement session the number of nuclei in a given area was manually counted, and compared with the data obtained by using automated image analysis in three histological samples. Since haematoxylin and eosin staining was adequate to discriminate between nuclei and cytoplasm of the muscle cells, automated image analysis counting of the nuclei was possible. Mucosal height was measured at five different and spaced sites. In the jejunum the height represents a perpendicular axis passing from the tip of the villus to the base of the crypt. Colonic measurements signify a perpendicular axis passing from the tip of the gland to the base of the crypt. All sections were coded so that the origin of the section was unknown to the observer. Before morphometric quantifications cross-sections were examined closely, and no signs of atrophy were observed in any of the experimental groups. Damaged tissue was not included in the image analysis.

\section{Statistical analysis}

Data are expressed as means with their standard errors. Group means were compared by ANOVA. Means were considered significantly different at $P \leq 0.05$, as determined by Fisher's protected least significant difference 
Table 2. Weight gain, faecal dry weight, gastrointestinal transit time (GTT), faecal bile acids and faecal neutral sterols in rats fed control, algal polysaccharide, algal biomass, or pectin-rich diets for $30 \mathrm{~d}^{*}$

(Values are means with their standard errors for seven rats per group)

\begin{tabular}{|c|c|c|c|c|c|c|c|c|}
\hline \multirow[t]{2}{*}{ Diet. . . } & \multicolumn{2}{|c|}{ Algal polysaccharide } & \multicolumn{2}{|c|}{ Algal biomass } & \multicolumn{2}{|c|}{ Pectin } & \multicolumn{2}{|c|}{ Control } \\
\hline & Mean & SE & Mean & SE & Mean & SE & Mean & SE \\
\hline Wt gain (g/30 d) & $103^{b}$ & 6 & $131^{a}$ & 2 & $119^{a}$ & 5 & $123^{\mathrm{a}}$ & 6 \\
\hline Faecal dry wt (g/d) & $2.78^{\mathrm{a}}$ & 0.07 & $2 \cdot 17^{\mathrm{b}}$ & 0.06 & $0.75^{d}$ & 0.02 & $0.94^{\mathrm{C}}$ & 0.03 \\
\hline GTT (h) & $13 \cdot 31^{a}$ & 0.74 & $6 \cdot 56^{\mathrm{b}}$ & 0.27 & $16 \cdot 21^{a}$ & 1.55 & $15 \cdot 06^{a}$ & 1.82 \\
\hline Faecal bile acids $(\mu \mathrm{mol} / \mathrm{d})$ & $7 \cdot 6^{\mathrm{b}}$ & 0.3 & $12 \cdot 2^{a}$ & 0.7 & $3 \cdot 7^{\mathrm{C}}$ & 0.3 & $2 \cdot 4^{\mathrm{C}}$ & 0.3 \\
\hline Faecal neutral sterols $(\mu \mathrm{mol} / \mathrm{d})$ & $39 \cdot 0^{\mathrm{a}}$ & $3 \cdot 0$ & \multicolumn{2}{|c|}{ ND } & $16 \cdot 5^{\mathrm{b}}$ & 0.4 & $12.9^{b}$ & 0.5 \\
\hline
\end{tabular}

$\mathrm{ND}$, not determined.

a,b,c,d Mean values in a row with unlike superscript letters were significantly different $(P<0.05)$.

${ }^{*}$ For details of diets and procedures, see Table 1 and p. 470.

method. For caecal viscosity measurements, data were log transformed to equalize variance.

\section{Results \\ Analysis of dietary fibre and fermentability}

The dietary fibre content of the algal biomass consisted of $27 \%$ insoluble and $8.5 \%$ soluble dietary fibre on a dry weight basis, whereas that of the polysaccharide was $37 \%$ soluble and $8 \%$ insoluble dietary fibre (Table 1$)$. In vitro fermentation experiments $(24 \mathrm{~h})$ demonstrated that the algal polysaccharide was resistant to bacterial breakdown (data not shown). In addition, the dietary fibre recovery in faecal samples was $80-105 \%$ for the cellulose-, biomassand polysaccharide-fed rats, while only $30 \%$ in rats fed the fermentable fibre pectin.

\section{Body weight gain and faecal dry weight}

Significantly lower weight gain $(P<0.005)$ was observed in polysaccharide-fed rats as compared with the control, biomass and pectin-fed rats (Table 2). Furthermore, faecal dry weight was significantly higher in the polysaccharidefed rats than all other experimental groups $(P<0.05)$. Biomass also significantly increased faecal dry weight in comparison with the pectin and control diets $(P<0.05)$.

\section{Gastrointestinal transit time}

The GTT was reduced $(P<0.05)$ in biomass-fed rats $(51-$ $60 \%$ ) compared with rats fed polysaccharide, pectin or control diets (Table 2).

\section{Plasma lipid levels}

Plasma cholesterol levels were significantly higher $(P<0.001)$ in control rats $(2.93(\mathrm{SE} 0.23) \mathrm{mmol} / \mathrm{l})$ than in rats fed the biomass (2.29 (SE 0.08) $\mathrm{mmol} / \mathrm{l})$, polysaccharide (2.08 (SE 0.09) mmol/l) or pectin (2.28 (SE 0.09) $\mathrm{mmol} / \mathrm{l}$ ) diets. Overall, polysaccharide feeding had the greatest hypocholesterolaemic effect. A trend towards lower plasma triacylglycerols was observed in rats fed polysaccharide, biomass and pectin in comparison with the control rats: 0.17 (SE 0.02) mmol/l, 0.17 (SE 0.01) mmol/l, 0.17 (SE 0.01$) \quad \mathrm{mmol} / \mathrm{l}$ and $0.24 \quad(\mathrm{SE} \quad 0.04) \quad \mathrm{mmol} / \mathrm{l}$ respectively.

\section{Faecal bile acids and neutral sterols}

Daily faecal bile acid excretion (Table 2) was lowest in the control animals, higher in the pectin-fed rats and significantly higher $(P<0.05)$ in the polysaccharide (twofold) and biomass fed rats (fourfold) compared with the control rats. Faecal neutral sterol excretion was significantly enhanced $(P<0.05)$ in rats fed the algal polysaccharide in comparison with control and pectin-fed rats.

\section{Cholecystokinin}

In week 3 of the experiment, $1 \mathrm{~h}$ following food withdrawal from rats, plasma CCK levels did not differ in biomass-fed and control animals. These levels were higher than those measured in both the polysaccharide- and pectin-fed rats (Table 3). A similar pattern was found in the duodenal mucosa at the termination of the experiment; CCK levels were significantly higher $(P<0.05)$ in biomass and control

Table 3. Effects of experimental diets on blood and mucosal cholecystokinin (CCK) levels in rats fed control, algal polysaccharide, algal biomass, or pectin-rich diets for $30 \mathrm{~d}^{*}$

(Values are means with their standard errors for seven rats per group)

\begin{tabular}{|c|c|c|c|c|c|c|c|c|}
\hline \multirow{2}{*}{ Diet. . . } & \multicolumn{2}{|c|}{ Algal polysaccharide } & \multicolumn{2}{|c|}{ Algal biomass } & \multicolumn{2}{|c|}{ Pectin } & \multicolumn{2}{|c|}{ Control } \\
\hline & Mean & SE & Mean & SE & Mean & SE & Mean & SE \\
\hline $\begin{array}{l}\text { CCK (pg/l)† } \\
\text { CCK (pg/l)‡ } \\
\text { CCK (pg/mg protein)§ }\end{array}$ & $\begin{array}{l}145 \cdot 0 \\
94.6 \\
0.77^{b}\end{array}$ & $\begin{array}{c}6.44 \\
13 \cdot 2 \\
0.82\end{array}$ & $\begin{array}{l}228.0 \\
111.9 \\
2.31^{\mathrm{a}}\end{array}$ & $\begin{array}{l}6.79 \\
3.5 \\
1.22\end{array}$ & $\begin{array}{l}148 \cdot 0 \\
80 \cdot 8 \\
0.68^{b}\end{array}$ & $\begin{array}{c}4 \cdot 08 \\
10 \cdot 3 \\
0.6\end{array}$ & $\begin{array}{l}193 \cdot 0 \\
110 \cdot 8 \\
2 \cdot 50^{\mathrm{a}}\end{array}$ & $\begin{array}{l}6 \cdot 31 \\
5 \cdot 5 \\
0 \cdot 76\end{array}$ \\
\hline
\end{tabular}

${ }^{a, b}$ Mean values in a row with unlike superscript letters were significantly different $(P<0.05)$.

* For details of diets and procedures, see Table 1 and p. 470 .

† Measured $1 \mathrm{~h}$ after ending the experimental diets (the rats were fed the experimental diets for $2 \mathrm{~h}$ after food had been withheld overnight).

$\ddagger$ Measured after food had been withheld overnight.

$\S$ Concentration in the mucosa that had been removed from the duodenum after food had been withheld overnight. 
Table 4. Morphometric measurements in rats fed control, algal polysaccharide, algal biomass, or pectin-rich diets for $30 \mathrm{~d}^{*}$

(Values are means with their standard errors for seven rats per group)

\begin{tabular}{|c|c|c|c|c|c|c|c|c|}
\hline \multirow[t]{2}{*}{ Diet. . . } & \multicolumn{2}{|c|}{ Algal polysaccharide } & \multicolumn{2}{|c|}{ Algal biomass } & \multicolumn{2}{|c|}{ Pectin } & \multicolumn{2}{|c|}{ Control } \\
\hline & Mean & SE & Mean & SE & Mean & SE & Mean & SE \\
\hline \multicolumn{9}{|l|}{ Intestinal length $(\mathrm{cm})$} \\
\hline Small intestine & $121^{a}$ & $2 \cdot 1$ & $109^{b}$ & 3.5 & $104^{\mathrm{b}}$ & 3.5 & $93^{c}$ & $2 \cdot 7$ \\
\hline $\begin{array}{l}\text { Colon } \\
\text { Jeiunum }\left(\mathrm{mm}^{2}\right)\end{array}$ & $17 \cdot 0^{\mathrm{a}}$ & 0.5 & $14 \cdot 0^{\mathrm{b}}$ & 0.3 & $14 \cdot 7^{\mathrm{b}}$ & 0.4 & $12 \cdot 9^{c}$ & 0.4 \\
\hline Total area & $6 \cdot 8^{a}$ & 0.73 & $5 \cdot 4^{\mathrm{ab}}$ & 0.59 & $4.9^{b}$ & 0.73 & $4 \cdot 3^{b}$ & 0.34 \\
\hline Mucosal area & $5 \cdot 5^{\mathrm{a}}$ & 1.5 & $4 \cdot 2^{a b}$ & 0.6 & $3.9^{b}$ & 0.3 & $3 \cdot 4^{\mathrm{b}}$ & 0.3 \\
\hline Muscularis area & $1 \cdot 3^{a}$ & 0.7 & $1 \cdot 2^{\mathrm{ab}}$ & 0.1 & $1.0^{\mathrm{bc}}$ & 0.7 & $0.9^{c}$ & 0.1 \\
\hline Nuclei $\left(/ 4.1 \mathrm{~mm}^{2}\right)$ & $17^{\mathrm{b}}$ & 0.9 & $19^{\mathrm{b}}$ & 0.1 & $17^{\mathrm{b}}$ & 0.9 & $22^{a}$ & 1.0 \\
\hline \multicolumn{9}{|l|}{ Colon $\left(\mathrm{mm}^{2}\right)$} \\
\hline Total area & $3.9^{b}$ & 0.27 & $4.9^{\mathrm{a}}$ & 0.27 & $4 \cdot 6^{a b}$ & $0 \cdot 11$ & $4 \cdot 7^{\mathrm{ab}}$ & 0.33 \\
\hline Mucosal area & $2 \cdot 8^{\mathrm{b}}$ & 0.2 & $3 \cdot 4^{\mathrm{a}}$ & 0.2 & $3 \cdot 5^{\mathrm{a}}$ & 0.2 & $2 \cdot 9^{a b}$ & 0.2 \\
\hline Muscularis area & $1 \cdot 1^{b}$ & 0.2 & $1.5^{\mathrm{ab}}$ & 0.1 & $1 \cdot 1^{b}$ & 0.1 & $1 \cdot 8^{\mathrm{a}}$ & 0.2 \\
\hline Nuclei $\left(/ 4.1 \mathrm{~mm}^{2}\right)$ & $11^{\mathrm{b}}$ & $1 \cdot 0$ & $12^{\mathrm{ab}}$ & $1 \cdot 0$ & $15^{\mathrm{a}}$ & $1 \cdot 0$ & $14^{\mathrm{a}}$ & 1.0 \\
\hline
\end{tabular}

a,b,c Mean values in a row with unlike superscript letters were significantly different $(P<0.05)$.

* For details of diets and procedures, see Table 1 and p. 470.

fed rats compared with polysaccharide- and pectin-fed rats. No significant differences in plasma hormone levels were observed in food-deprived rats.

\section{Viscosity of caecal contents}

In control animals, caecal content viscosity was $1 \cdot 1$ (SE $0.05) \mu P a . s$ and in pectin-fed animals 1.9 (SE 0.10) $\mu$ Pa.s. Consumption of algal biomass significantly elevated viscosity to 24.0 (SE 3.1) $\mu$ Pa.s. Caecal viscosity in the rats fed the non-fermentable algal polysaccharide was significantly higher $(P<0.0001)$ than that in all other groups, 349 (SE 36.7) $\mu$ Pa.s.

\section{Morphometric measurements}

Feeding all three fibre-rich diets resulted in a significant elongation $(P<0.05)$ of both the small intestine and colon in comparison to control rats (Table 4). Despite the lower weight gain in the rats fed the algal polysaccharide, intestinal elongation was significantly greater $(P<0.05)$ than all other groups of animals. Small intestine length was $23 \%$ greater than that in the control animals, while colon length was $29 \%$ greater (Table 4). In the jejunum, polysaccharide feeding had the greatest effect on the morphology of both the mucosa and tunica muscularis layers. Although pectin- and biomass-fed animals showed a trend towards increased jejunal areas, the polysaccharide diet produced significant differences $(P<0.05)$ in mucosal area, $38 \%$ greater in comparison with the controls. In addition, muscularis area was increased by $30 \%$ (Table 4 and Figs. 1 and 2). Biomass and pectin feeding had a lesser impact on the jejunum mucosal mass, with increased areas of 19 and $13 \%$ respectively. Jejunal muscularis area was greatest in the polysaccharide-fed rats and smallest in the control animals. Furthermore, control rats had significantly more nuclei per $\mathrm{mm}$ muscularis area than rats fed the experimental diets (Fig. 2).

In contrast to the jejunum, changes in the mid-colon tissue morphology were less apparent. An 18-20\% increase in mucosal area was observed in the biomass- and pectin-fed animals in comparison with the polysaccharide-fed and control animals. The total cross-sectional areas, therefore, did not differ, while the tunica muscularis cross-sectional area was significantly larger in the control group than in the polysaccharide-fed rats $(P<0 \cdot 005)$. Overall, the effect on morphometric variables was less evident in pectin-fed rats than in the other experimental groups.

\section{Discussion}

The present study examined the metabolic and morphological changes in rats following feeding with biomass or polysaccharide from the red microalga Porphyridium sp. Both the biomass and the polysaccharide from this alga influenced the intestinal structure and significantly reduced plasma cholesterol levels $(P<0 \cdot 05)$. The work described here illustrates some of the unique properties of dietary fibre derived from algae, and potential health benefits of incorporating these foodstuffs into the diet.

Rats fed the algal polysaccharide gained less weight than rats in other experimental groups, despite similar food intake levels (data not shown). Furthermore, dry faecal weight was more than double in the polysaccharide-fed animals. In general, diets with a fibre content of $50 \mathrm{~g} / \mathrm{kg}$ do not influence animal growth (Anderson et al. 1994). The lower weight gain of the polysaccharide-fed rats may be due to the high viscosity of the intestinal contents following food consumption. The viscosity of the caecal contents of rats fed algal polysaccharide was more than 300 -fold higher than that of the control animals and more than 180-fold higher than that of the pectin-fed rats. Highly-viscous chyme is thought to impede nutrient absorption and micelle formation, and may decrease overall lipid absorption, which would result in lower weight gain (Nagengast, 1992; Gallaher et al. 1993; Schneeman \& Richter, 1993; Lairon, 1996).

Morphological changes in the intestine following fibre feeding may also influence absorption and facilitate the metabolic changes induced by fibre feeding (Brown et al. 1979; Schneeman \& Richter, 1993; Stark et al. 1996). Changes in the structure of the villus have been reported 

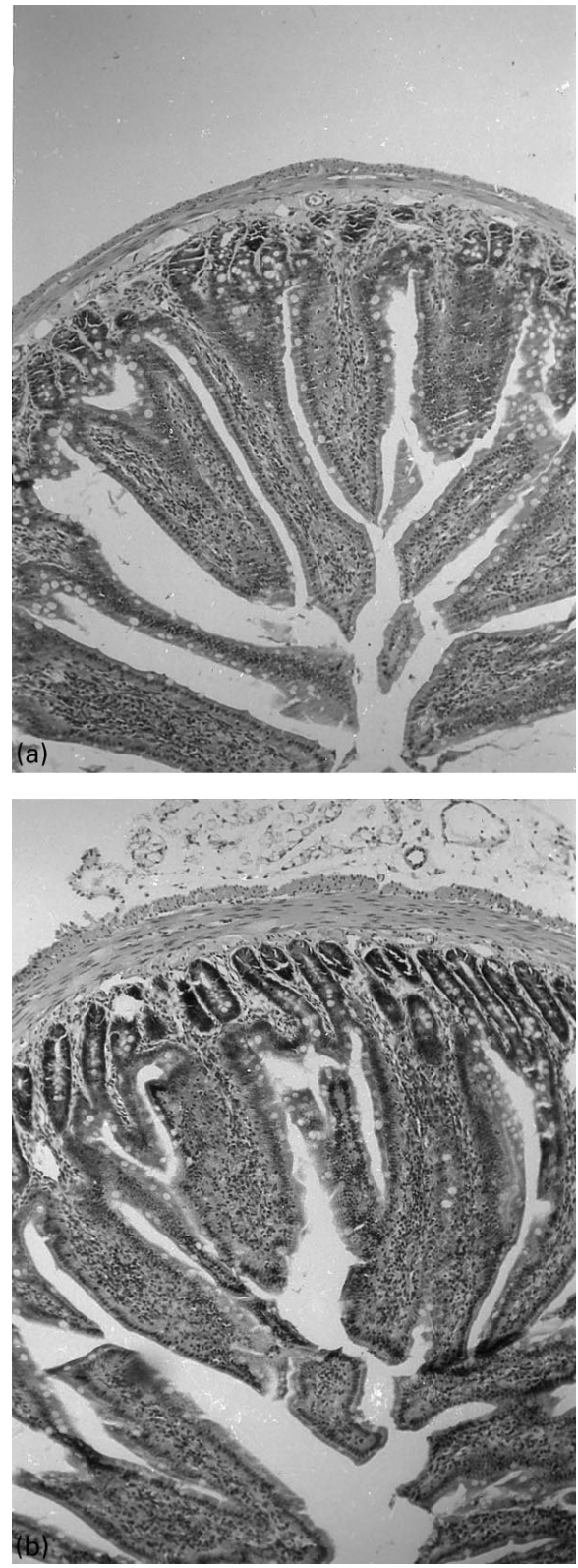

Fig. 1. Photomicrographs of transversal sections of the jejunum from a control rat $(A)$ and from a rat fed the polysaccharide diet $(B)$ for $30 \mathrm{~d}$. Note that the thickness of the tunica muscularis layer in $(B)$ is almost double that in the control (A). For details of diets and procedures, see Table 1 and p.470. Haematoxylin and eosin stain; $\times 200$.

following fibre feeding in rats (Cassidy et al. 1981; Vahouny \& Cassidy, 1986), and it has also been shown that soluble fibre significantly $(P<0.001)$ increases intestinal length (Jacobs, 1983; Judd \& Truswell, 1985; Stark et al. 1996). Distinct changes in the intestinal morphology were observed following algal polysaccharide, biomass and pectin diets. In all experimental groups lengthening of the small intestine and the colon was observed, with the greatest effect being in polysaccharidefed rats. Intake of high-fibre diets leads to a downward shift in nutrient absorption (Read \& Eastwood, 1992); therefore, intestinal elongation may be an adaptive mechanism to
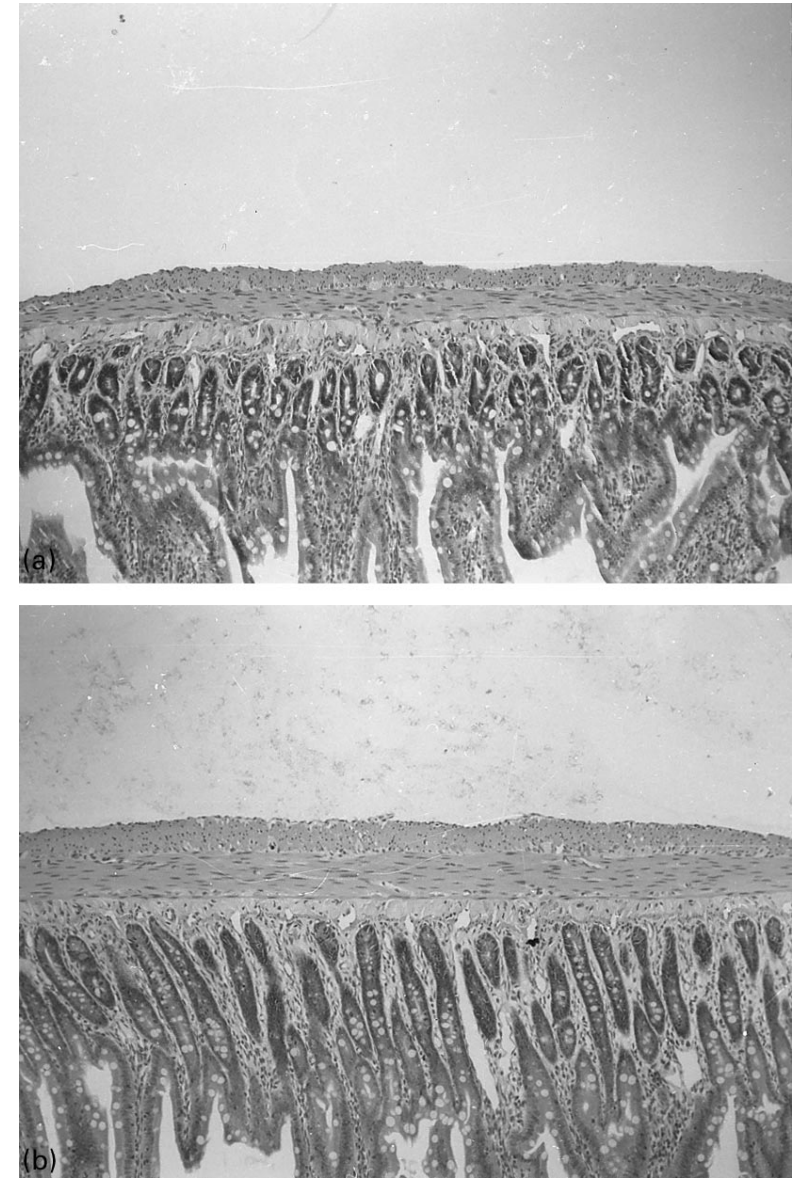

Fig. 2. Higher magnification photomicrograph of transversal sections of the jejunum of a control rat $(A)$ and of rat fed the polysaccharide diet (B) for $30 \mathrm{~d}$. Note the number of nuclei per unit area (density) in the inner layer of the tunica muscularis layer; it is markedly reduced in the polysaccharide-fed rats $(B)$ than in the control $(A)$. For details of diets and procedures, see Table 1 and p. 470. Haematoxylin and eosin stain; $\times 350$.

maximize nutrient absorption. Additionally, it appears that the highly viscous nature of the biomass and algal polysaccharide leads to structural modifications in the small intestine necessary to overcome the increased work required to move its contents forward (increased muscularis layer) as well as to greater mucosal volume to maximize nutrient absorption. In the colon total cross-sectional areas of biomass-fed rats were similar to those of the controls, but the relative area of mucosa was greater. This finding may be due to bacterial fermentation in the colon of the biomass-fed rats and increased production of short-chain fatty acids, the preferred source of energy for colonocytes. Pectin, which is fermented in the large intestine, also caused an enlargement in the relative colonic mucosal area, while the non-fermentable polysaccharide did not. By counting the nuclei it was shown that changes in muscularis in both the large and small intestine of rats fed biomass and algal polysaccharide were caused by cell hypertrophy. This finding suggests an adaptive response to dietary intervention rather than a pathological occurrence. It has been demonstrated that hypertrophy signifies an increase in size 
or volume of the cell, usually arising from an increased workload (Cheville, 1994). Precisely how morphological changes may modify nutrient absorption and lipid metabolism is still not well understood.

GTT may be an important factor in nutrient absorption. GTT was dramatically reduced in the biomass-fed rats in comparison with the other two experimental groups and control animals. Although fibre intake commonly shortens GTT (Saito et al. 1991), it is not clear why the red microalgal biomass had such a marked effect in comparison with other fibre sources (Table 2). Biomass feeding led to higher CCK plasma levels in comparison with pectin and polysaccharide feeding (Table 3). The role of CCK in the regulation of GTT is not yet fully understood and no detailed studies examining the effect of dietary fibre on CCK release have been published. However, it has been observed that this hormone has a potent effect on gut smooth muscle contractility, depending on the region of the gut. CCK also causes contraction of the gall bladder, relaxation of the sphincter of Oddi, relaxation of the gastric fundus and contraction of the intestine (Grider, 1994). Nevertheless, CCK secretion can only partially explain the shortened GTT caused by biomass consumption, since serum and mucosal CCK levels were elevated only in comparison with pectin- and polysaccharide-fed rats. Thus, other factors must be involved in the dramatic decrease in GTT associated with algal biomass consumption.

A significant hypocholesterolaemic effect $(P<0.05)$ was observed following administration of diets containing pectin, algal biomass and algal polysaccharide (all containing approximately $50 \mathrm{~g}$ soluble dietary fibre $/ \mathrm{kg}$ ) in comparison with animals fed the control diet. Different dietary fibre varies considerably in its physical properties and chemical composition, therefore characterization of hypocholesterolaemic mechanisms is very complex (Eastwood \& Morris, 1992). It has also been suggested that disruption of the entero-hepatic circulation of bile acids leads to increased bile acid excretion and a subsequent decrease in plasma cholesterol levels (Topping et al. 1990; Glore et al. 1994). Significantly increased bile acid excretion $(P<0.05)$ was measured in rats fed the algal polysaccharide and biomass (Table 2). Daily faecal bile acid excretion was highest in the biomass-fed animals (five times higher than that in the control group) but was also significantly elevated $(P<0.05)$ following polysaccharide consumption. The findings of the present study support the theory that disruption of entero-hepatic circulation of bile acids leads to increased bile acid excretion and a subsequent decrease in plasma cholesterol levels. In addition, neutral sterol excretion was significantly enhanced in algal polysaccharide-fed rats (Table 2), representing another pathway by which cholesterol pools are depleted by fibre feeding.

Other proposed mechanisms of action for the hypocholesterolaemic activity of dietary fibre include direct inhibition of hepatic sterol synthesis. It has been hypothesized that the short-chain fatty acids produced by fermentation of soluble fibre may act in this manner (Chen et al. 1984; Kishimoto et al. 1995). In an additional study carried out in our laboratory (I Dvir, R Chayoth, U Sod-Moriah, S Shany, A Nyska, AH Stark, Z Madar and
S Malis Arad, unpublished results) using algal dietary fibre, levels of hydroxymethylglutaryl-CoA reductase, the key enzyme in cholesterol synthesis, were determined. Algal polysaccharide significantly enhanced endogenous synthesis of cholesterol in comparison with cellulose-fed controls, indicating that direct hepatic inhibition of cholesterol synthesis does not result from algal polysaccharide feeding.

In conclusion, both algal polysaccharide alone and algal biomass, with their unique dietary fibre make-up of sulfated polysaccharide, induce morphological modifications in the intestine and have potent hypocholesterolaemic properties. Several possible mechanisms appear to be involved in the induction of the hypocholesterolaemic effect, including increased faecal bile acid and neutral steroid excretion, increased intestinal viscosity and modified GTT. The red microalga Porphyridium sp., a source of unique dietary fibre, may prove to have significant health benefits when consumed in relatively small amounts and provide therapeutic effects similar to, or better than, those of more traditional sources of plant fibre.

\section{References}

Allain CC, Poon LS, Chan CSG, Richmond W \& Fu PC (1974) Enzymatic determination of total serum cholesterol. Clinical Chemistry 20, 470-475.

American Institute of Nutrition (1977) Report of the American Institute of Nutrition ad hoc committee on standards for nutritional studies. Journal of Nutrition 107, 1340-1348.

American Institute of Nutrition (1980) Second report of the ad hoc committee on standards for nutritional studies. Journal of Nutrition 110, 1726.

Anderson JW, Jones AE \& Riddell-Mason S (1994) Ten different dietary fibers have significantly different effect on serum and liver lipids of cholesterol-fed rats. Journal of Nutrition 124, 78-83.

Bajpai P \& Bajpai P (1993) Eicosapentaenoic acid (EPA) production from microorganisms: a review. Biotechnology 30, 161-183.

Bradford MM (1976) A rapid and sensitive method for the quantitation of microgram quantities of protein utilizing the principle of protein-dye binding. Analytical Biochemistry 72, 248-256.

Brown NJ, Worlding J, Rumsey RDE \& Read NW (1979) Active and inactive forms of 3-hydroxy-3-methylglutaryl coenzyme A reductase in the liver of the rat. Journal of Biological Chemistry 254, 5144-5149.

Cassidy MM, Lightfoot FG, Grau LE, Story JA, Kritchevsky D \& Vahouny GV (1981) Effect of chronic intake of dietary fibers on the ultrastructural topography of rat jejunum and colon: a scanning electron microscope study. American Journal of Clinical Nutrition 34, 218-228.

Chen WL, Anderson JW \& Jennings D (1984) Propionate may mediate the hypocholesterolemic effects of certain soluble plant fibers in cholesterol fed rats. Proceedings of the Society for Experimental Biology and Medicine 175, 215-218.

Cheville NF (1994) Pathologic cell growth. In Ultrastructural Pathology. An Introduction and Interpretation, pp. 193-228 [NF Cheville, editor]. Ames, IA: Iowa State University Press.

Cohen E \& Malis Arad S (1989) A closed system for outdoor cultivation of Porphyridium. Biomass 18, 59-67.

Davidson MH \& McDonald A (1998) Fiber: forms and function. Nutritional Research 18, 617-624. 
Eastwood MA \& Morris ER (1992) Physical properties of dietary fiber that influence physiological function: a model for polymers among the gastrointestinal tract. American Journal of Clinical Nutrition 55, 436-442.

Fabregas J \& Herrero C (1990) Vitamin content of four marine microalgae potential use as source of vitamins in nutrition. Industrial Microbiology 5, 259-264.

Folch J, Lees M \& Sloan-Stanley GH (1957) A simple method for the isolation and purification of total lipids from animal tissues. Journal of Biological Chemistry 226, 497-509.

Fossati P \& Prencipe L (1982) Serum triglycerides determined colorimetrically with an enzyme that produces hydrogen peroxide. Clinical Chemistry 28, 2077-2080.

Gallaher DD, Hassel CA, Lee K \& Gallaher CM (1993) Viscosity and fermentability as attributes of dietary fiber responsible for the hypocholesterolemic effect in hamsters. Journal of Nutrition 123, 244-252.

Geresh S \& Malis Arad S (1991) The extracellular polysaccharide of red microalgae: chemistry and rheology. Bioresource Technology 38, 195-201.

Glore SR, Van Treeck D, Knehans AW \& Guild M (1994) Soluble fiber and serum lipids: a literature review. Journal of the American Dietetic Association 94, 425-436.

Grider JR (1994) Role of cholecystokinin in the regulation of gastrointestinal motility. Journal of Nutrition 124, 1334S1339S.

Jacobs LR (1983) Effects of dietary fiber on the mucosal growth and cell proliferation in the small intestine of the rat: a comparison of oat bran, pectin, and guar with total fiber deprivation. American Journal of Clinical Nutrition 37, 954-960.

Jones TM, Anderson AJ \& Albersheim P (1963) Studies on the growth of the red alga Porphyridium cruentum. Plant Physiology 16, 636-643.

Judd PA \& Truswell AS (1985) The hypocholesterolemic effect of pectin in rats. British Journal of Nutrition 53, 409-425.

Kishimoto Y, Shigeru W \& Hidetoshi T (1995) Hypocholesterolemic effect of dietary fiber: relation to intestinal fermentation and bile acid excretion. Journal of Nutritional Science and Vitaminology 41, 151-161.

Lahaye M (1991) Marine algae as sources of fibers: Determination of soluble and insoluble dietary fiber contents in some 'sea vegetables'. Journal of Food Science and Agriculture 54, 587594.

Lahaye M \& Jegou D (1993) Chemical and physical-chemical characteristics of dietary fibers from Ulva lactuca (L.) Thuret and Enteromorpha compressa (L.) Grev. Journal of Applied Physiology 5, 195-200.

Lairon D (1996) Dietary fibres: effects on lipid metabolism and mechanisms of action. European Journal of Clinical Nutrition 50, 125-133.

Lopes-Virella MF, Stone P, Ellis S \& Colwella JA (1977) Cholesterol determination in high-density lipoproteins separated by three different methods. Clinical Chemistry 23, 882884.

Lopez-Alonso D, Molina-Grima E, Sanchez-Perez JA, GarciaSanchez JL \& Garcia-Camacho F (1992) Isolation of clones of Isochrysis galbana rich in eicosapentaenoic acid. Aquaculture 102, 363-371.
Mabeau S \& Fleurance J (1993) Seaweed in food products: biochemical and nutritional aspects. Trends in Food Science and Technology 4, 103-107.

Malis Arad S (1988) Production of polysaccharides from red unicellular algae. In Algal Biotechnology, pp. 65-87 [T Stadler, J Mollion, MD Verdus, Y Karamanos, H Morvan and D Christiaen, editors]. London: Elsevier Applied Science.

Nagengast FM (1992) Dietary fiber and bile acid metabolism. In Dietary fiber - A Component of Food, Nutritional Function in Health and Disease, pp. 217-231 [TF Schweizer and CA Edwards, editors]. London: Springer-Verlag.

Nuutila AM, Aura AM, Kiesvaara M \& Kauppienen V (1997) The effect of salinity, nitrate concentration, $\mathrm{pH}$ and temperature on eicosapentaenoic acid (EPA) production by red unicellular alga Porphyridium purpureum. Biotechnology 55, 55-63.

Prosky L, Asp N, Schweizer TF, DeVries JW \& Furda I (1988) Determination of insoluble, soluble and total dietary fiber in food and food products: Interlaboratory study. Journal of the Association of Official Analytical Chemists 71, 1017-1023.

Read NW \& Eastwood MA (1992) Gastro-intestinal physiology and function. In Dietary fiber - A Component of Food, Nutritional Function in Health and Disease, pp. 103-117 [TF Schweizer and CA Edwards, editors]. London: Springer-Verlag.

Saito T, Hayakawa T, Nakamura K, Takita T, Suzuki K \& Innami S (1991) Fecal output, gastrointestinal transit time, frequency of evacuation and apparent excretion rate of dietary fiber in young men given diets containing different levels of dietary fiber. Journal of Nutritional Science and Vitaminology 37, 493-508.

Schneeman BO \& Richter D (1993) Changes in plasma and hepatic lipids, small intestinal histology and pancreatic enzyme activity due to aging and dietary fiber in rats. Journal of Nutrition 123, 1328-1337.

Searcy RL \& Bergquist LM (1960) A new color reaction for quantitation of serum cholesterol. Clinica Chimica Acta 5, 192-199.

Sheltawy MJ \& Losowsky MS (1975) Determination of fecal bile acids by an enzymatic method. Clinica Chimica Acta 64, 127132.

Slavin G, Sowter C, Robertson K, Mcdermott S \& Paton K (1980) Measurement in jejunal biopsies by computer-aided microscopy. Journal of Clinical Pathology 33, 254-261.

Southgate DAT (1990) Dietary fiber and health. In Dietary Fiber: Chemical and Biological Aspects, pp. 10-19 [DAT Southgate, K Waldron, IT Johnson and GR Fenwick, editors]. Cambridge: The Royal Society of Chemistry.

Stark A, Nyska A \& Madar Z (1996) Metabolic and morphometric changes in small and large intestine in rats fed high-fiber diets. Toxicologic Pathology 24, 166-171.

Topping DL, Ilman RJ, Dowling K \& Trimble RP (1990) Mechanisms whereby fibre could lower plasma cholesterol. In Dietary Fiber: Chemical and Biological Aspects, pp. 300-304 [DAT Southgate, K Waldron, IT Johnson and GR Fenwick, editors]. Cambridge: The Royal Society of Chemistry.

Vahouny GV \& Cassidy MM (1986) Dietary fiber and intestinal adaptation. In Dietary Fiber - Basic and Clinical Aspects, pp. 253-264 [GV Vahouny and D Kritchevsky, editors]. New York: Plenum Press. 